\title{
OPTIMIZATION OF NICKEL CONTENT ON SOME PROPERTIES OF (NITI) SHAPE MEMORY ALLOY
}

\author{
Nabaa S. Radhi ${ }^{1}$, Karrar F. Morad ${ }^{1}$, Mohammad H. Hafiz², Alaa Abdulhasan Atiyah ${ }^{3}$, Aissa Bouaissi ${ }^{4, *}$ \\ ${ }^{1}$ University of Babylon/Department of Metallurgy Engineering/ Babil, Iraq. \\ ${ }^{2}$ Iraqua University-Baghdad-Iraq. \\ ${ }^{3}$ Department of Materials Engineering, University of Technology, Baghdad, Iraq. \\ ${ }^{4}$ School of Engineering, University of Plymouth, Plymouth PL4 8AA, UK. \\ *Corresponding: aissabouaissi@yahoo.fr
}

\begin{abstract}
Shape Memory Alloys (SMAs) are one of the most hopeful smart materials, especially, Nickel-Titanium (NiTi or Nitinol). These alloys are great and desirable due to their excellent reliability and behavior among all the commercially available alloys. In addition, strain recovery, (Ni-Ti) is granulated for a wide variety of medical uses because of its favorite properties such as fatigue behavior, corrosion resistance and biocompatibility. This paper explores the creation and the characterization of functionally graded (NiTi) materials. This work demonstrations the impact of Nickel contains changes on the characteristics of NiTi shape memory alloy, in order to obtain the suitable addition of Nickel contain, which gives the optimal balance between hardness, start and finish martensitic point, shape recovery and shape effect of alloys properties. These materials are prepared to obtain suddenly or gradually microstructure or composition differences inside the structure of one piece of material, the specimens made by powder metallurgy process and the influence of every layer of composite by; micro-hardness, transformation temperature DSC and shape effect. The hardness value and shape recovery decrease with increase nickel content. superior shape memory effect (SME) and shape recovery (SR) properties (i.e., 8.747, 10.270 for SMA-FGM1 SMA-FGM2 respectively, and SR is 1.735, 2.977 for SMA-FGM1 SMAFGM2) respectively.
\end{abstract}

Keywords: Smart materials; shape memory alloy functionally graded materials (SMA-FGM); DSC and shape effect.

\section{Introduction}

In general, shape memory alloys (NiTi) can be found in two different phases named Martensite and Austenite. Depending on the temperature of crystalline structures, the Martensite forms in low temperatures, while the Austenite produces in high temperatures or main phase [1], [2]. Both (Austenitic and Martensitic) NiTi have many different properties, such as Young modulus, electrical resistance and damping behavior [1-3]. Therefore, the Austenite consists of a Central Cubic structural Body (BCC), where the nickel atom located at the centre of the crystallographic cube, while the titanium atom can be found at each cube's corners from eight corners. Further, the Austenitic phase is considered as the main phase, due to its symmetrical microstructure. However, in comparison with the Austenitic phase, the NiTi Martensite's phase is considered as less symmetrical and lattice structure, and it has a rhombus alignment, where the atoms located at each rhombus corners [4-8].

Under a temperature effect, the Austenite can be converted into a Martensite phase in the atomic scale, this behavior is known as Thermoelastic Martensitic Transformation (TMT) [11]. It is reported that the TMT has a substantial effect on the functional characteristics, in which the minimum energy limit for a specific temperature need to be localized by the structure of crystalic lattice $[9,10]$. Therefore, the TMT and its reversion can be prevented by a shear-dominant in the solid phase condition, which lead to converting the Martensitic phase from the main phase (Austenitic) by nucleation. Moreover, the TMT activation process has an impact on the NiTi alloys, which can be converted from Austenite to Martensite and conversely, by either decreasing the temperature (Thermally Induced Martensite, (TIM)) or by setting a mechanical stress (Stress Induced Martensite, (SIM)). However, Martensite can be converted to Austenite phase by either increasing the temperature or get rid of the set stress. Thus, both mechanical and thermal stresses have a different effect on NiTi alloys.

(FGMs) is an advanced material, which has been introduced in the early 1980s in Japan. This material was produced in order to increase the need for materials with high adhesion and low thermal stresses, especially in composites metal-ceramic materials used in rocket engines [14]. At the same time, FGMs term becomes promising for most researchers around the world and they used FGMs to improve the components with superior physical characteristics of materials (metals, ceramics and organic composites) [15]. Different methods can be used to produce the structure gradients based on the uses and the loading state. Then coatings applied by various 
methods including sol-gel, pulsed laser deposition (PLD), arc spraying, plasma spraying, and chemical and physical vapor deposition (CVD and PVD) methods.

Recently, the development of composite materials is mainly based on the production of functionally graded structures. These functionally graded materials are new engineering materials class, where their microstructure and composition differ in one direction. Generally, functionally graded materials made from continued changing in the materials composition without a specific interface. Thus, generally assumed that the functionally graded structures have better resistance to thermal and mechanical stress.

Therefore, the application of this concept on metal matrix composites (MMCs) can be a reason for the development and the designing of different components, such as reinforcing the materials in places which required more modulus, strength and wear resistance. The FGMs refer to the grading in the material characteristics, and this can play a significant role in the industrial uses, especially the use of MMCs [16].

Qinglin Meng et al in 2010, have investigated a fundamental thermodynamic question about the temperature intervals of the B2-B19' martensitic transformation in a Ti-50.2 at\% Ni alloy. Temperature intervals of thermoplastic transformations are considered to be caused by internal elastic energies produced by the formation of martensite (in case of the forward transformation). The intervals have been traditionally measured by differential scanning calorimetry analysis (DSC) [17].

Qinglin Meng et al in 2012, created a functionally graded NiTi thin plates with varying composition through the thickness. The composition gradient is created by surface diffusing Ni into thin equi-atomic NiTi plates. The compositional gradient results in a gradient of the critical temperatures for martensitic transformation in the alloy. The functionally graded NiTi plates exhibit unique all-round shape recovery behavior in a "fishtail-like" motion. Such mechanical behavior offers new options for innovative designs of $\mathrm{NiTi}$, in particular actuators and bionics devices [18].

Nabaa Sattar et. al. [14], prepared seven layers NiTi alloys functionally graded materials by powder metallurgy as well as the two models of functionally graded materials. The effect of layers composition, sintering time and temperatures was studied on the transformation temperature, as well as the developmental phases. Nabaa Sattar et. al. [9], the fabrication phase of research starts with the design and development of functionally graded NiTi materials consists of axisymmetric seven layers incorporated into single functionally graded materials. Four different compositions and thickness were considered. The composition of layers is (atomic percent) as follow: $50 \mathrm{Ti}-50 \mathrm{Ni}, 49.3 \mathrm{Ti}-50.7 \mathrm{Ni}, 48.5 \mathrm{Ti}-51.5 \mathrm{Ni}$ and $47.8 \mathrm{Ti}-52.2 \mathrm{Ni}$.

Corrosion rate and characteristics as well as the toxicity of sintered materials are investigated also, corrosion test results show that the current of corrosion (Icorr.) for SMA-FGM samples are less than that obtained at each layer (i.e.,19.02, $15.32 \mu \mathrm{A} / \mathrm{cm} 2$ for SMA-FGM1 SMA-FGM2) respectively, and Nickel ions percentage in Ringer solution after corrosion test show SMA-FGM1 SMA-FGM2 samples less than each layer.

The aim of the present research are design, fabrication and characterization of multi NiTi shape memory alloys incorporated into single functionally graded materials. This design assumed to improve the general properties of NiTi shape memory alloys, especially the transformation temperature range. These materials are designed to have gradual microstructural or compositional variations within the body in one piece or single material.

\section{Materials and Methodology}

The materials were used in the preparation of SMA -FGMs layers are Nickel and Titanium in powder forms and their properties are shown in Table 1.

Table 1: Nickel and Titanium in powder properties.

\begin{tabular}{cccc}
\hline Powder & Average particle size $(\boldsymbol{\mu m})$ & Purity \% & Origin. \\
\hline Nickel & 33 & 99.8 & BDH Chemicals Ltd Poole England \\
Titanium & 165 & 98.5 & Fluke Chemi AGCH-9470 Bucks \\
\hline
\end{tabular}

\section{Experimental work plan}

During this investigative study, the experimental has been carried out as follows:

i. The preparation of the FGM layers following the model profile design displayed in Tables 2 and 3.

ii. Mixing the powders in a wet phase for seven hours.

iii. Filling the molds cavity with the powder's mixture following stepwise controlled method.

iv. Pressing and compacting the powders mixture inside the molds.

v. Sintering process in a vacuum oven with Argon as an inert gas.

vi. Hardness tests were separately conducted on each layer of the prepared samples to examine the gradation of properties along with the thickness.

vii. Studying the DSC and shape effect behavior of the samples. 
Table 2: SMA-FGM1 Model's Profile.

\begin{tabular}{ccc}
\hline Layers & Thickness $(\mathbf{c m})$ & Chemical composition \% wt \\
\hline 1 & 0.05 & $(45 \mathrm{Ti}-55 \mathrm{Ni})$ \\
2 & 0.178 & $(44.2 \mathrm{Ti}-55.8 \mathrm{Ni})$ \\
3 & 0.307 & $(43.5 \mathrm{Ti}-56.5 \mathrm{Ni})$ \\
4 & 0.435 & $(42.7 \mathrm{Ti}-57.3 \mathrm{Ni})$ \\
5 & 0.307 & $(43.5 \mathrm{Ti}-56.5 \mathrm{Ni})$ \\
6 & 0.178 & $(44.2 \mathrm{Ti}-55.8 \mathrm{Ni})$ \\
7 & 0.05 & $(45 \mathrm{Ti}-55 \mathrm{Ni})$ \\
\hline
\end{tabular}

Table 3: SMA-FGM 2 Model's Profile

\begin{tabular}{ccc}
\hline Layers & Thickness $(\mathbf{c m})$ & Chemical composition \% wt \\
\hline 1 & 0.05 & $(42.7 \mathrm{Ti}-57.3 \mathrm{Ni})$ \\
2 & 0.178 & $(43.5 \mathrm{Ti}-56.5 \mathrm{Ni})$ \\
3 & 0.307 & $(44.2 \mathrm{Ti}-55.8 \mathrm{Ni})$ \\
4 & 0.435 & $(45 \mathrm{Ti}-55 \mathrm{Ni})$ \\
5 & 0.307 & $(44.2 \mathrm{Ti}-55.8 \mathrm{Ni})$ \\
6 & 0.178 & $(43.5 \mathrm{Ti}-56.5 \mathrm{Ni})$ \\
7 & 0.05 & $(42.7 \mathrm{Ti}-57.3 \mathrm{Ni})$ \\
\hline
\end{tabular}

\section{Results and Discussion}

In order to test the shape effect, the shape memory and the shape recovery, the specimens were cooled down below the Martensite finish temperature $\left(M_{f}\right)$ and then loaded at the Austenit temperature $\left(A_{s}\right)$ to detain the Martensite. After unloading, the samples were heated up to recover the Austenit and the original shape. In this study, there is a used compression test to define the shape memory effect characteristics of the prepared samples. Hence, the changes in the SME properties according to the chemical composition of the prepared alloys and functionally graded samples were detailed in this study.

Shape memory impact and shape recovery were determined from the compression test. The shape memory impact and shape recovery values for all produced specimens are exhibited in Figures 1 and 2. The SME properties of each layer samples were increased with the decrease of the Nickel content, for instance, the SME for the $1^{\text {st }}$ layer sample with the chemical composition of $45 \%$ wt and Ni-Ti $55 \%$ wt is $6.846 \%$, while the SME for the $2^{\text {nd }}$ layer sample with the chemical composition of $44.2 \%$ wt and Ni-Ti $55.8 \%$ wt is $6.410 \%$. Figure 1 illustrates the values of the SME as a function to the chemical composition of the produced specimens. This improvement in SME characteristics of $\mathrm{Ni}-\mathrm{Ti}$ alloys is ascribed due to the presence of $\mathrm{Ni}_{3} \mathrm{Ti}$ phase. This phase which formed in the Ni-Ti alloys strongly improved the SME characteristics of the alloys.

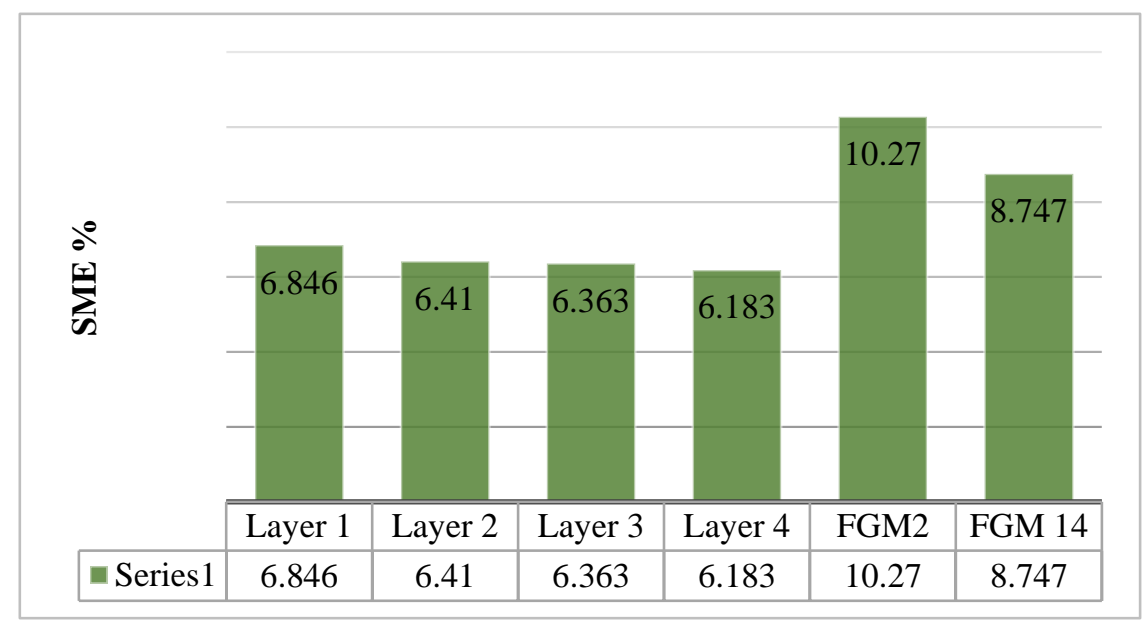

Figure 1: Influence of chem. Comp. on SME characteristics gained from compression test at RT temp. 


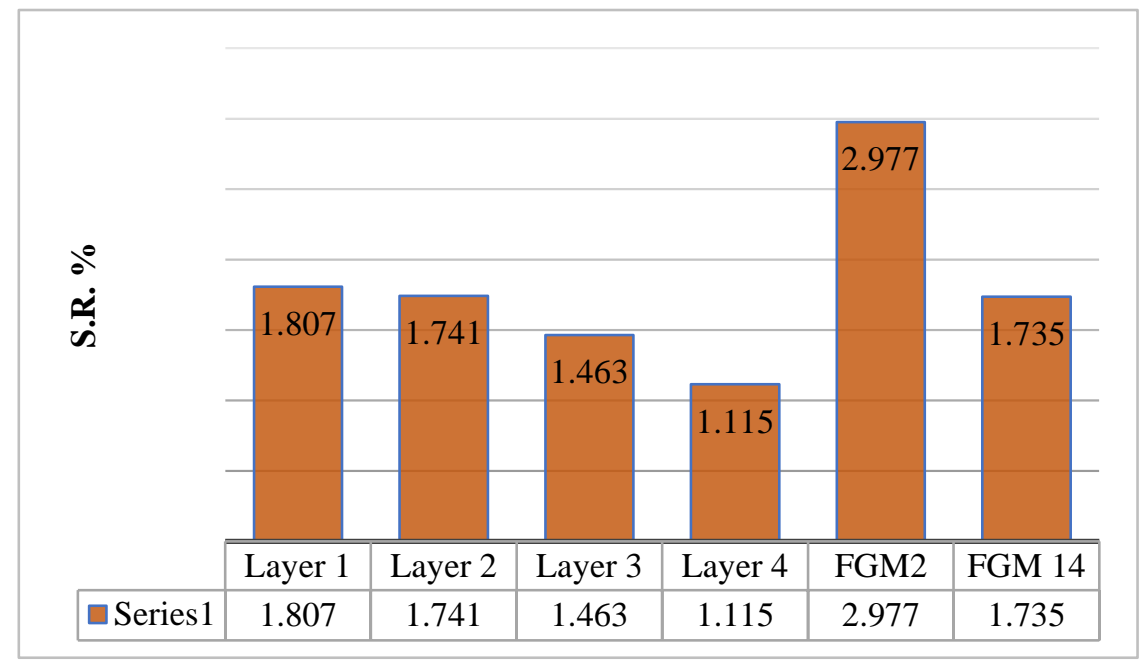

Figure 2: Influence of chem. Comp. on strain recovery characteristics gained from compression test at RT temp.

In addition, $\mathrm{SMA}-\mathrm{FGM}_{1}$ and $\mathrm{SMA}-\mathrm{FGM}_{2}$ can be illustrated by the values of SMA, which were higher than each layer samples by $8.747 \%$ and $10.270 \%$, respectively. Figure 3 shows the effect of the Nickle content of the shape recovery of alloys, it can be observed that the Ni content dramatically decreased, when the Ni amount ranges from $56 \%$ to $57 \%$, with a decreasing percentage varied from $1.7 \mathrm{sr} \%$ to $1.1 \mathrm{sr} \%$, respectively.

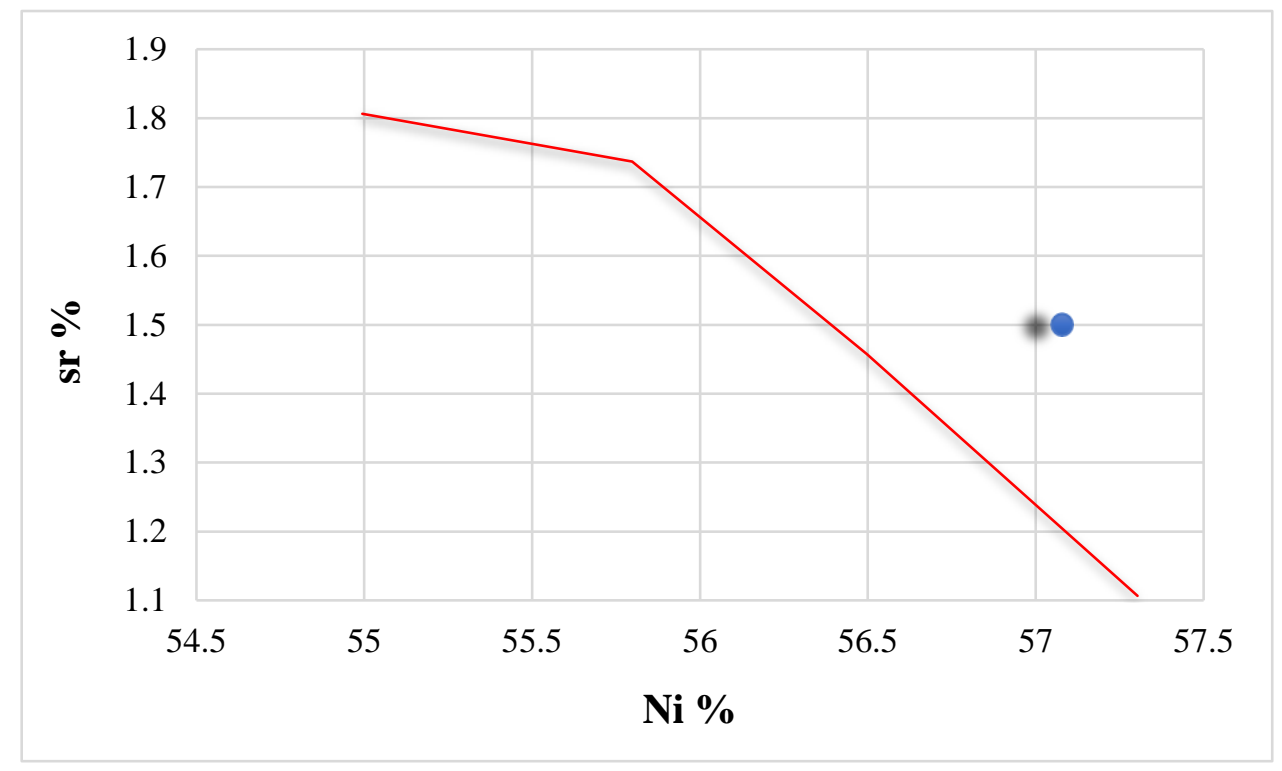

Figure 3: Influence of Nickel amount on shape recovery of alloys.

Martensite is well-known as a ductile and softer steel crystalline structure when compared with Austenite. Whereas, Austenite is considered stronger and hardness [16,17]. Therefore, it is noticeable that the availability of phase Martensite is more than the Austenite phase from those samples which consist of steel. Hence, in this discussion, we will consider that a pure Martensite phase has a low value for hardness. Further, a negative relationship between the hardness and the Ni\% as shown in Figures 4 and 5. 


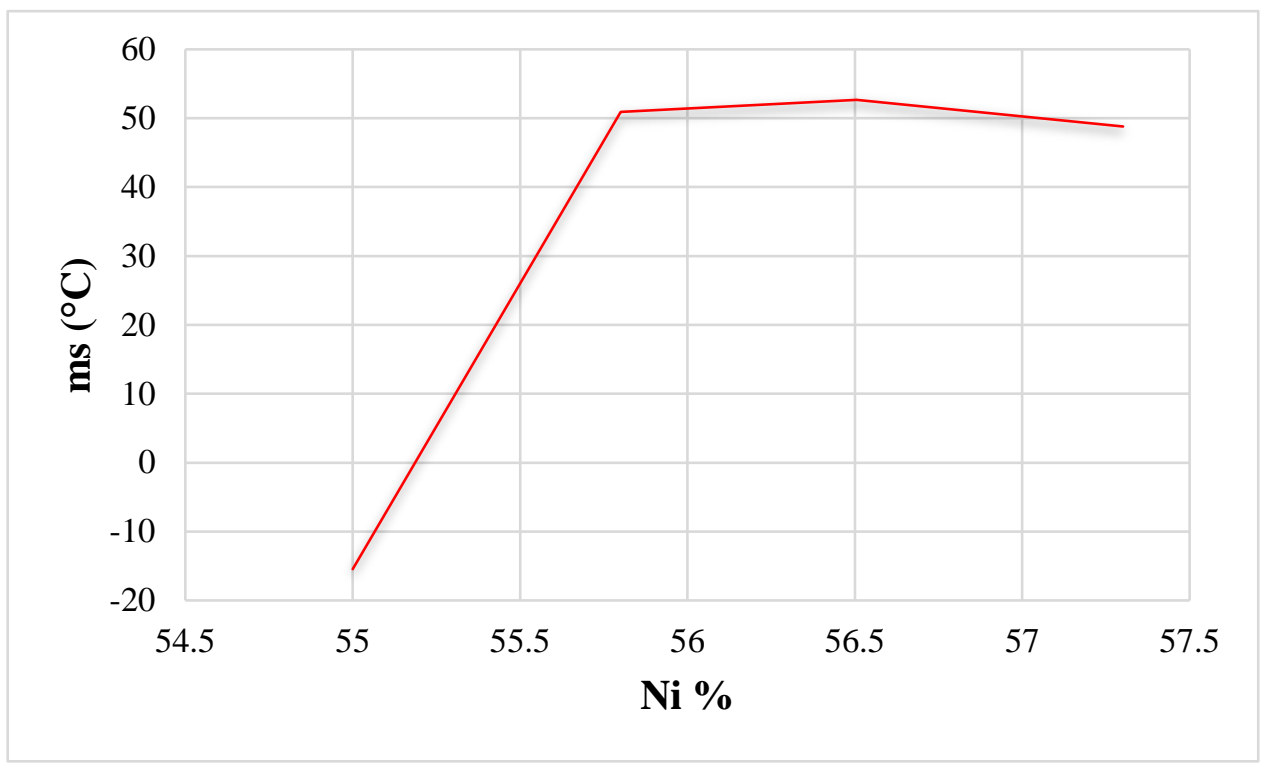

Figure 4: Effect of Nickel amount on start martensitic point of alloys.

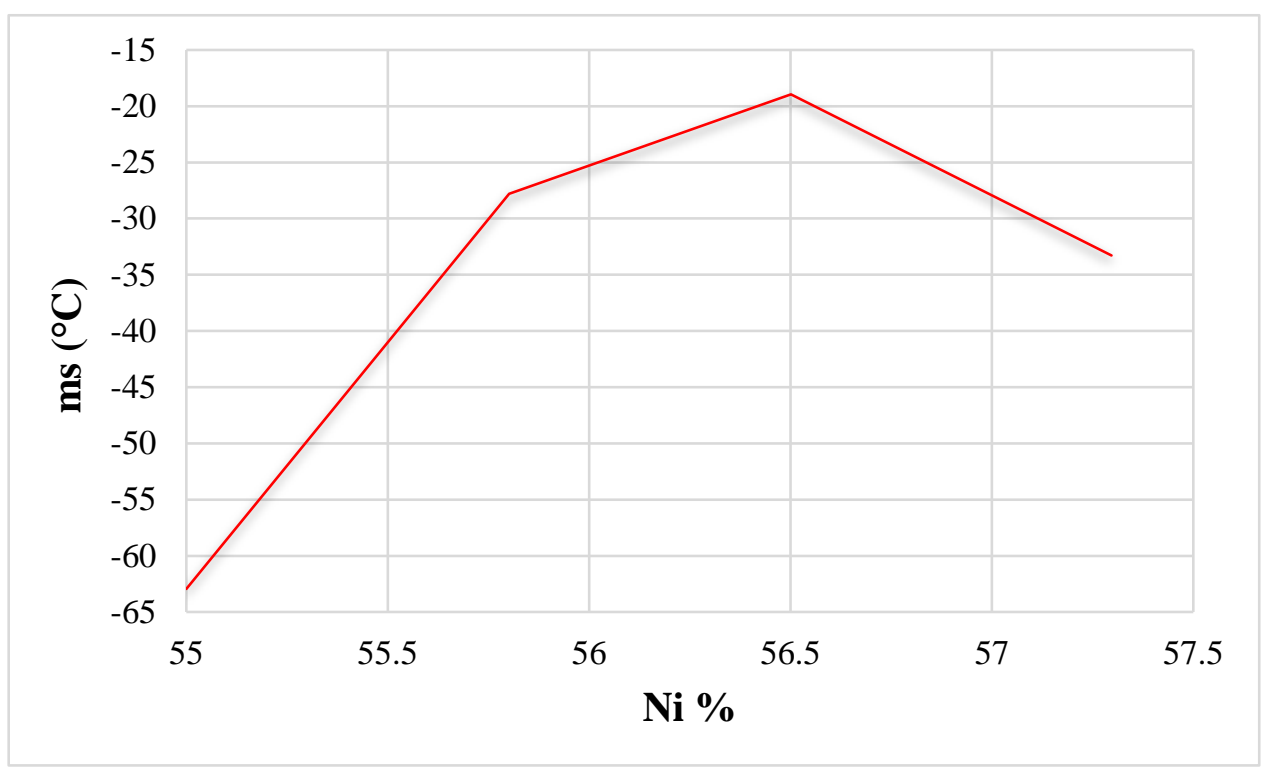

Figure 5: Influence of Nickel amount on finishing martensitic point of alloys.

The microhardness test results obtained are exhibited in Figures 6, 7,8 and 9. It is clear that the optimal nickel content in NiTi has a significant impact on the determination of the optimal properties of SME. Figures 7 and 8 show the measured hardness values for the functionally graded samples. Martensite is known as a high ductile and softer steel crystalline structure, when compared with Austenite which is stronger and hardness [13 -15]. Thus, the samples are ductile and soft compared with the pure Austenitic phase (which has more strength). This compatible with the nature of each one, for example, the thermal one deforms at room temperature, but it is flexible, so it returns to its original shape under heat effect (as the shape memory effect) while the Austenitic phase is not returning (it is just super-elastic). 


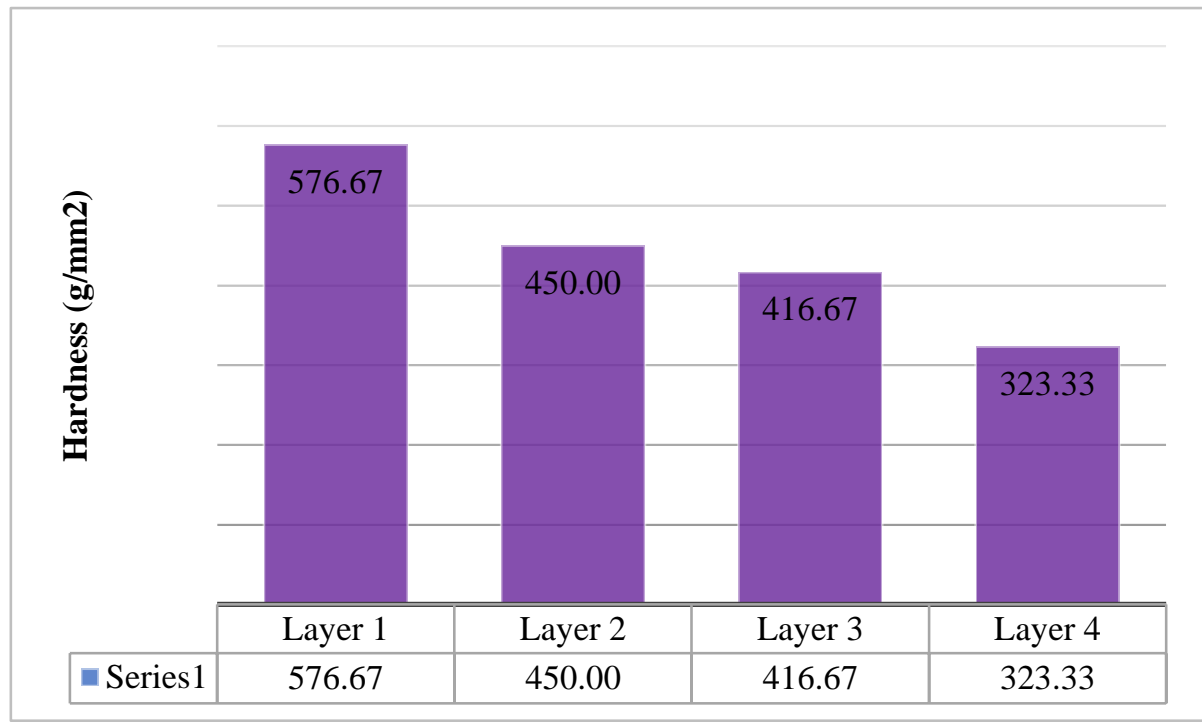

Figure 6: Micro-hardness for samples with different layers composition.

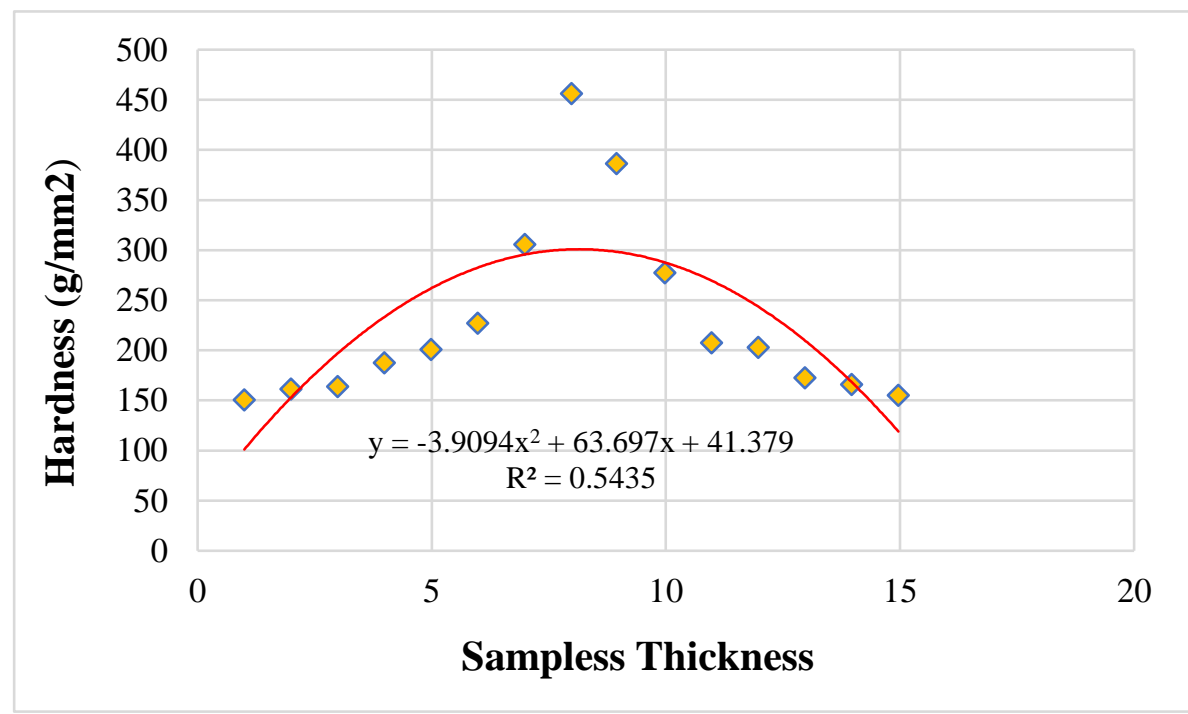

Figure 7: Micro-hardness for SMA-FGM 1 samples with different thickness.

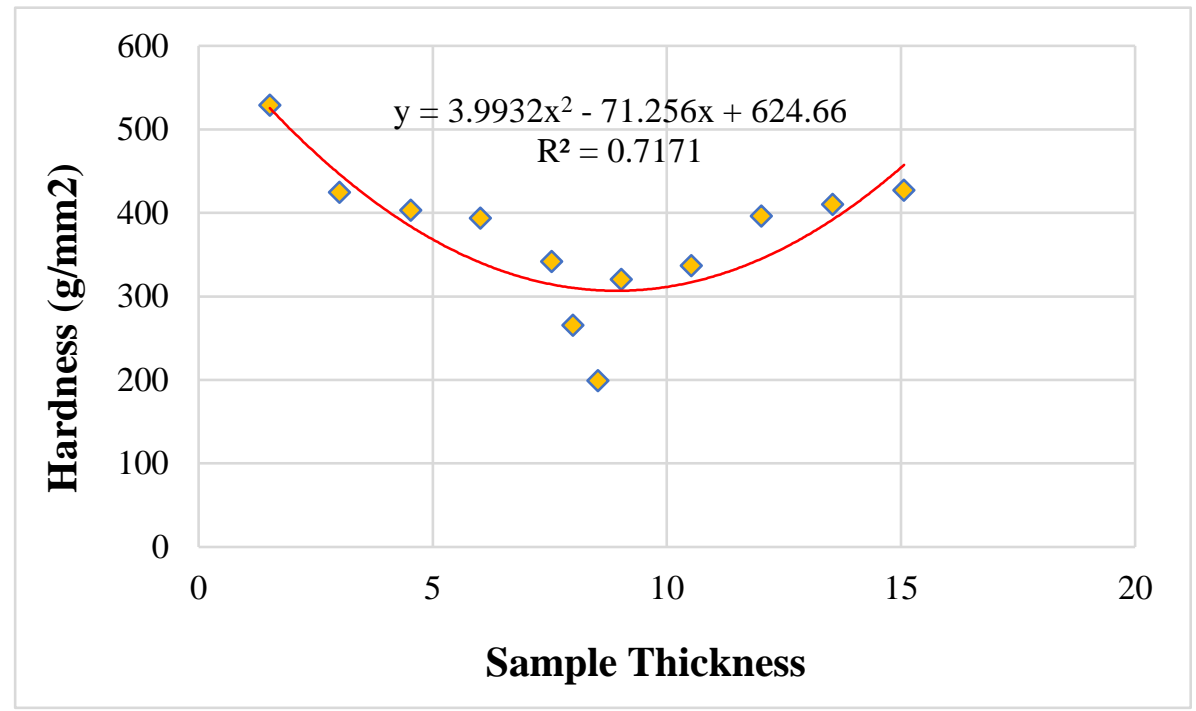

Figure 8: Micro-hardness for SMA-FGM 2 samples with different thickness. 


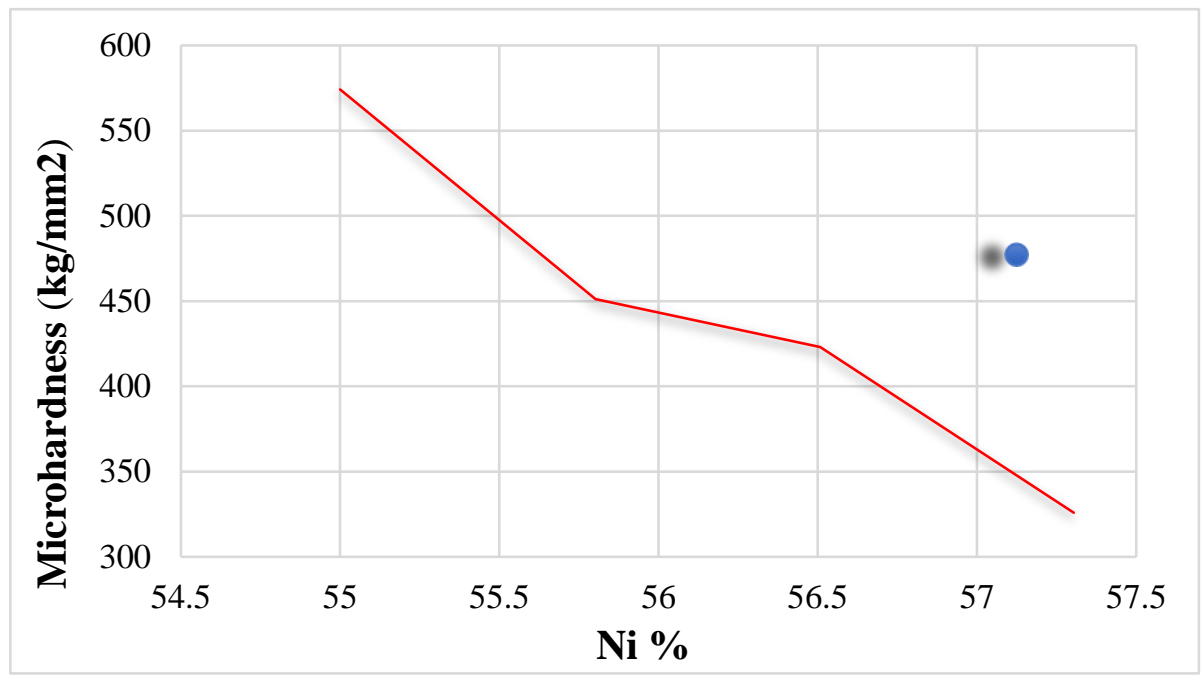

Figure 9: Influence of Nickel contain on micro-hardness value of alloys.

\section{Conclusions}

Based on the results and discussion, following conclusions can be drawn:

i. To achieve a linear constituent's difference, a functionally graded materials design with asymmetric seven layers along with the layers has been proposed.

ii. The sintering at $\left(950^{\circ} \mathrm{C} \pm 5^{\circ} \mathrm{C}\right)$ for 7 hours of the produced specimens seems to be sintered effectively and converted the $\mathrm{Ni}$ and the $\mathrm{Ti}$ into alloy structure.

iii. At room temperature, all samples are resulting in three-phase structures (i.e., NiTi monoclinic phase, $\mathrm{NiTi}$ cubic phase and hexagonal $\mathrm{Ni}_{3} \mathrm{Ti}$ phase).

iv. $\quad$ DSC results showed a change in temperature ranged from 26 to $97^{\circ} \mathrm{C}$.

v. Shape memory influence and shape recovery properties for SMA-FGMs samples upper values for each layer the SME 8.747, 10.270 for SMA-FGM1 SMA-FGM2 respectively and SR 1.735, 2.977 for SMA-FGM1 SMA-FGM2 respectively.

Conflict of interest: The authors declare no conflict of interest to any party.

\section{References}

[1] Y. Zhang and X. Xu, "Transformation temperature predictions through computational intelligence for NiTi-based shape memory alloys," Shape Memory and Superelasticity, pp. 1-13, 2020.

[2] B. Xu, G. Kang, C. Yu, and Q. Kan, "Phase field simulation on the grain size dependent super-elasticity and shape memory effect of nanocrystalline NiTi shape memory alloys," International Journal of Engineering Science, vol. 156, p. 103373, 2020.

[3] N. S. Radhi, "Preparation, Characterization, and Modeling Functionally Graded Materials in Bioapplication.” PhD thesis. University of Technology. Iraq, 2015.

[4] N. M. Dawood, "Preparation \& Characterization of Coated \& Cu alloyed Bio Nitinol." Ph. D. Thesis, University of technology. Fabricated from Special Thermo ..., 2014.

[5] M. H. Al-Jaberi, M. A. Al-Dabbas, and R. Al-Khafaji, "ASSESSMENT OF HEAVY METALS CONTAMINATION AND SEDIMENT QUALITY IN SHATT AL-ARAB RIVER, S IRAQ,” The Iraqi Geological Journal, pp. 88-97, 2016.

[6] K. Otsuka and X. Ren, "Physical metallurgy of Ti-Ni-based shape memory alloys," Progress in materials science, vol. 50, no. 5, pp. 511-678, 2005.

[7] A. Falvo, M. L. Luchi, and F. Fugiuele, "Thermomechanical characterization of Nickel-Titanium shape memory alloys." 2007.

[8] M. A. Sadeq, "Corrosion behavior of biocompatible coatings of porous NiTi shape memory alloy." Ph. D. Thesis, Production Engineering and Metallurgy Department, University ..., 2013.

[9] N. S. Radhi and Z. Al-Khafaji, "Investigation biomedical corrosion of implant alloys in physiological environment," International Journal of Mechanical and Production Engineering Research and Development, vol. 8, no. 4, 2018.

[10] Z. S. Al-khafaji, N. S. Radhi, and S. A. Mohson, "Preparation and modelling of composite materials (polyester-alumina) as implant in human body," International Journal of Mechanical Engineering and 
Technology, vol. 9, no. 4, 2018.

[11] Y. Soejima, A. Heima, H. Akamine, T. Inamura, and M. Nishida, "Comparison of In Situ SEM and TEM Observations of Thermoelastic Martensitic Transformation in Ti-Ni Shape Memory Alloy," Materials transactions, vol. 61, no. 11, pp. 2107-2114, 2020.

[12] K. Otsuka and C. M. Wayman, Shape memory materials. Cambridge university press, 1999.

[13] B. Al-Zubaidy, N. S. Radhi, and Z. S. Al-Khafaji, "Study the effect of thermal impact on the modelling of (titanium-titania) functionally graded materials by using finite element analysis," International Journal of Mechanical Engineering and Technology, no. 1, 2019.

[14] N. Radhi, M. Hafiz, and A. Atiyah, "Preparation and Investigation of Corrosion and Biocompatibility Properties for Functionally Graded Materials (NiTi)," Ind Eng Manage S, vol. 3, pp. 316-2169, 2018.

[15] N. S. L. Khafaji, M. H. Hafiz, and A. A. Atiyah, "Sintering of Incorporated Shape Memory Alloys into Functionally Graded Materials," Ind Eng Manage S, vol. 3, pp. 316-2169, 2018.

[16] N. M. Dawood, N. S. Radhi, and Z. S. Al-khafaji, "Investigation Corrosion and Wear Behavior of Nickel-Nano Silicon Carbide on Stainless Steel 316L," vol. 1002, pp. 33-43, 2020.

[17] M. Koizumi and M. Niino, “Overview of FGM research in Japan,” Mrs Bulletin, vol. 20, no. 1, pp. 1921, 1995.

[18] A. Mortensen and S. Suresh, "Functionally graded metals and metal-ceramic composites: Part 1 Processing," International materials reviews, vol. 40, no. 6, pp. 239-265, 1995. 